\title{
Г. УОЛТЕРС ${ }^{1}$
}

${ }^{1}$ Университет Куцттаун, г. Куцттаун, шт. Пенсильвания, США

\section{РАЦИОНАЛЬНОСТЬ И НЕРАЦИОНАЛЬНОСТЬ РЕШЕНИЯ О СОВЕРШЕНИИ ПРЕСТУПЛЕНИЯ*}

Цель: обоснование необходимости учета влияния эмоций на процесс принятия решений; дать представление о комбинированной модели процесса принятия решений, объединяющей рациональные и нерациональные компоненты выбора при совершении преступления.

Методы: диалектический, системный, историко-правовой, формально-юридический, обобщения.

Результаты: в работе осуществлен комплексный анализ процесса принятия решения о совершении преступления, а также изучены факторы, повышающие вероятность совершения антиобщественных деяний. Ценность комбинированной когнитивно-эмотивной модели в том, что эмоции могут дать принимающему решение человеку более значимую информацию, чем рассуждение.

Научная новизна: автор выдвигает теорию принятия решений, согласно которой человек совершает выбор в пользу того или иного действия или бездействия под влиянием гедонистических и нравственных эмоций, причем нерелевантные эмоции усиливаются, а релевантные подавляются когнитивными и ситуативными факторами, служащими в конечном итоге основой выбора в пользу преступления.

Практическая значимость: изучение роли эмоций в процессе принятия криминальных и некриминальных решений внесет значимый вклад в развитие криминологии. Результаты исследования будут полезны научным и правоприменительным работникам, также всем тем, кто интересуется вопросами пресечения и предупреждения правонарушений.

Ключевые слова: криминология; теория рационального выбора; нравственные эмоции; гедонистические эмоции; действующий преступник; мышление; реактивное криминальное мышление

Как цитировать статью: Уолтерс Г. Рациональность и нерациональность решения о совершении преступления // Актуальные проблемы экономики и права. 2016. T. 10, № 3. С. 252-270. DOI: http:// dx.doi.org/10.21202/1993-047X.10.2016.3.252-270

\section{Введение}

Теория рационального выбора, основанная на ранних философских работах Чезаре Беккариа (Cesare Beccaria)

\footnotetext{
* Впервые статья опубликована в Criminology, Criminal Justice, Law \& Society and The Western Society of Criminology Hosting by Scholastica. All rights reserved. Статья находится в открытом доступе в соответствии с Creative Commons Attribution Non-Commercial License (http://creativecommons.org/licenses/by-nc/3.0/), предусматривающем некоммерческое использование, распространение и воспроизводство на любом носителе при условии упоминания оригинала статьи. Для коммерческого использования обратитесь в редакцию журнала Criminology, Criminal Justice, Law \& Society (CCJLS) и The Western Society of Criminology: CCJLS@ WesternCriminology.org.

Цитирование оригинала статьи на английском языке: Walters G. D. (2015). Decision to Commit Crime: Rational or Nonrational, The. Criminology, Criminal Justice, Law \& Society, 16, 1.
}

(1738-1794) и Иеремии Бентама (Jeremy Bentham) (1748-1832) и положившая начало классической школе криминологии, является главной движущей силой современной криминологии. Она лежит в основе ряда важнейших криминологических теорий, среди которых можно назвать теорию устрашения [1], рутинных действий [2], социального обучения [3], общую теорию напряжений [4], теорию социального взаимодействия [5] и общую теорию преступлений [6], а также известного подхода к контролю над преступностью - ситуативной профилактики преступности [7]. В отличие от детерминистских теорий преступности и правосудия теория рационального выбора утверждает, что преступники и не-преступники различаются лишь выбором, который они совершают. Цель данной статьи - изучить роль эмоций в процессе выбора и разработать альтернативный взгляд на выбор в пользу преступления, который объ-

Уолтерс Г. Рациональность и нерациональность решения о совершении преступления

Walters G. D. Decision to commit crime: rational or nonrational 
единил бы рациональные и нерациональные элементы процесса выбора в пользу преступления.

Теория рациионального выюора

Теория рационального выбора (далее - ТРВ) основывается на нескольких принципах, семь из которых перечислены ниже [8]:

1. Рациональность - человек действует рационально.

2. Полезность - действующее лицо оценивает соотношение средство/результат в рамках процесса принятия решения.

3. Гедонизм - при оценке соотношения средство/ результат действующее лицо стремится максимизировать удовольствие и минимизировать страдания.

4. Ожидания - решение принимается исходя из ожидания удовольствия или страдания.

5. Социальное взаимодействие - решение, принятое действующим лицом, является результатом анализа затрат и выгод различных доступных ему сценариев в конкретный момент времени.

6. Ограниченная рациональность - действующее лицо оценивает альтернативы в рамках своих ограниченных знаний и возможностей.

7. Наказание - эффективность юридических или метаюридических санкций является функцией определенности, скорости и суровости наказания.

ТРВ во многом опирается на экономические теории выбора $[9,10]$, но без использования сложных математических формул, с помощью которых экономисты вычисляют затраты и выгоды. Наиболее известной и получившей наибольшее эмпирическое подтверждение версией ТРВ в криминологии является подход «Криминальное мышление», предложенный Cornish и Clarke [11, 12]. Рассматривая процесс принятия криминального решения, Cornish и Clarke [12] предположили, что преступник оценивает вероятные последствия своих действий до совершения преступления. Их целью, однако, было не объяснение процесса принятия криминального решения, а обоснование политики ситуационной профилактики преступлений [13]. Поэтому, признавая, что рациональность преступника ограничена его способностями к обработке информации, ситуационным контекстом и эмоциями, они не включили эти понятия в свою теорию [14]. Важнейшим ограничением ТРВ в целом и подхода Cornish и Clarke [12] в частности является игнорирование аффективных и эмоциональных аспектов самого преступления и процесса принятия криминального решения [15]. Таким образом, хотя ТРВ хорошо объясняет экономические/имущественные преступления, она не может полноценно объяснить неэкономические или аффективные преступления [16].

Рассматривая эволюцию теорий нерационального выбора в экономике, Zafirovski [17] считает, что от одной трети до половины всех экономических решений включают в себя эмоциональный или нерациональный выбор, действия или результаты. Pratt и Cullen [18], в своем метаанализе исследований в области теории рационального выбора и преступности показали, что макроиндикаторы уголовного права, относящиеся к ТРВ, способны лишь в слабой степени предсказывать криминальное поведение и что введение социальной политики устрашения, начиная от укрупнения отделов полиции и заканчивая ужесточением законодательства, практически не влияет на уровень преступности. Сравнительный анализ трех основных компонентов теории устрашения - определенности, скорости и суровости наказания - показывает, что лишь один из них (определенность) оказывает влияние на уровень преступности, да и то в небольшой степени [1]. Исследования показывают, что ТРВ не может эффективно предсказать и снизить уровень преступности. Наша работа призвана доказать, что для этого необходимо учитывать влияние эмоций на процесс принятия решений.

Рассматривая ограничения ТРВ, ряд исследователей указывают на роль эмоции и аффекта в процессе принятия криминальных решений. Так, Lindegaard, Bernasco, Jacques и Zevenbergen [19] изучали роль эмоций в совершении грабежа путем опроса 76 преступников. Они обнаружили, что различные эмоции являются определяющими на различных стадиях процесса грабежа, при этом до и во время грабежа главенствующей эмоцией был страх, а после грабежа - радость. Исследуя студентов мужского и женского пола, Bouffard [20] показал, что сексуальное возбуждение воспринимается ими как одно из субъективных преимуществ принуждения при сексуальном контакте. Исследуя две группы студентов, Van Gelder, Reynald и Elffers [21] выявили, что под влиянием гнева испытуемые стремятся отомстить тому, кто, по их мнению, вызывал их гнев, даже если при этом они осознают несправедливость своей реакции или лишаются возможности достичь своей цели. Таким 
образом, в данной работе мы предполагаем, что более глубокое изучение роли эмоций в процессе принятия криминальных и некриминальных решений внесет значимый вклад в развитие криминологии.

\section{Эмоции в процессе принятия решений. Связь эмоций и выбора}

Криминологи считают ТРВ недостаточной для полного объяснения преступности по нескольким причинам. Во-первых, она не может объяснить аффективные преступления и роль импульсивного решения при совершении такого рода правонарушений. Исследуя данную проблему, Forgas [22] показал, что негативные психические состояния часто приводят к снижению импульсивности и сокращению рискованных решений, тогда как позитивные психические состояния повышали степень импульсивности и способствовали принятию рискованных решений. Десятилетием позже Gordon и Arian [23] подтвердили, что ситуационные факторы играют важную роль во взаимосвязи эмоций и процесса принятия решений. Их исследование доказало, что эмоции оказывают значительное влияние на процесс принятия решений в условиях повышенной угрозы. Однако в условиях пониженной угрозы решение принимается под совместным влиянием эмоций и логики. Другое исследование показало, что когнитивное модулирование эмоций снижает степень импульсивности и рискованных решений, в отличие от испытуемых, которые получали указание не использовать когнитивные способности для модулирования своих эмоций [24].

Эмоции могут не только мешать процессу принятия решений, но и способствовать ему. Damasio [25] выдвинул гипотезу соматических маркеров, объясняющую, как эмоции используются для принятия решений. Основное положение данной гипотезы состоит в том, что, помимо оценки субъективных затрат и выгод определенного образа действия, люди оценивают также эмоциональное качество каждого из возможных результатов действия. Damasio [25] определяет соматические маркеры как ассоциации между побуждающими стимулами и физиологическими реакциями (конкретные эмоции плюс соответствующие им телесные реакции). Эти физиологические реакции побуждают индивида к одним действиям («ощущение правильного действия») и отвращают от других («ощущение неправильного действия»).
По сути, соматические маркеры упрощают и ускоряют процесс принятия решений. По мнению Damasio [25], телесные реакции и аффект взаимодействуют двумя различными способами: во-первых, телесные или соматические реакции проецируются напрямую в мозг, где вызывают эмоции («телесная петля»: изображение змеи вызывает страх), во-вторых, мысленное представление эмоции вызывает данную эмоцию и соответствующую телесную или соматическую реакцию («как бы телесная петля»: мысль о возможности увидеть змею вызывает реакцию страха).

\section{Нейроанатомическое обоснование}

Гипотеза соматических маркеров Damasio [25] подразумевает, что эмоции влияют на процесс принятия решений через специфические структуры мозга. Согласно гипотезе, в лобной коре головного мозга эмоции сопрягаются с телесными сигналами, оказывая влияние на принимаемые решения. Повреждения в данной области мозга нарушают обработку соматических и эмоциональных реакций и вызывают целый ряд антиобщественных проявлений [26]. Согласно гипотезе соматических маркеров, активность в боковых отделах лобной коры регулирует процесс принятия решений. Фактически нейронная активность в этих областях может как подавлять эмоциональную информацию, нерелевантную для данного решения, так и усиливать эмоциональную информацию, релевантную в данном контексте [27]. Лобная кора, возможно, участвует также в комплексном эмоционально-перцептивном процессе эмпатии [28]. Она является частью паралимбической системы. Основная лимбическая структура, мозжечковая миндалина, также может играть ведущую роль в процессе принятия решений благодаря своему воздействию на эмоции. Отмечается, что мозжечковая миндалина создает эмоциональный отклик, определяющий отношения между решением и его результатом - наградой или наказанием [29]. Индивидуумы с поврежденной мозжечковой миндалиной лишены этой важнейшей обратной связи [30]. По результатам последних исследований, мозжечковая миндалина участвует в когнитивном модулировании эмоций в процессе принятия решений [31]. Богатое дофамином полосатое тело мозга (хвостатое ядро и скорлупа) - еще одна область мозга, являющаяся возможным медиатором между эмоциями и процессом принятия решений. Последние исследования показывают, что у индивидуумов с антиобщественным

Уолтерс Г. Рациональность и нерациональность решения о совершении преступления

Walters G. D. Decision to commit crime: rational or nonrational 
поведением полосатое тело мозга плохо обрабатывает отсутствие вознаграждения; следовательно, организм продолжает отвечать на бесполезные стимулы так, как будто получает вознаграждение [32].

\section{Контекст психологии развития}

Процесс принятия решений можно рассматривать также в контексте психологии развития. Вряд ли можно ожидать от 8-летнего ребенка того же уровня способности принимать решения, что и от 18-летнего человека. Последние имеют больше жизненного опыта, более развитое мышление и, следовательно, в большей степени способны принимать осознанные решения. Влияние эмоций, ситуационных факторов, лимбических и стриарных структур мозга на процесс принятия решений также будет зависеть от возраста. Blakemore и Robbins [33], например, отмечают, что подростки более склонны принимать рискованные решения, чем маленькие дети и взрослые, особенно в условиях эмоционального состояния, в присутствии сверстников и в ситуации угрозы самоуважению. Такие «напряженные» ситуации мешают процессу рационального выбора и повышают вероятность принятия рискованного решения.

Маленькие дети часто сообщают о чувстве радости после совершения морального проступка [34], однако подростки, особенно старшие, чаще испытывают положительные эмоции при выборе морального поведения [35]. Возможно, это результат развития эмпатии. Формирование эмпатии происходит под влиянием нескольких факторов развития, важнейшие из которых описываются в теории психической деятельности, показывающей, как ребенок учится понимать мысли, чувства, знания и намерения других людей [36]. Исследования показывают, что теория психической деятельности охватывает как когнитивные, так и аффективные аспекты, причем последние продолжают развиваться в подростковый период, вызывая изменения в лобной коре $[33,37,28]$.

\section{Роль темперамента}

Описывая способы, с помощью которых криминальное принятие решений способствует криминальному поведению, необходимо помнить, что принятие решения - это функция эмоций и когнитивных способностей, которые, в свою очередь, являются функцией определенных нейроанатомических и психических факторов. Эти нейроанатомические и психические факторы составляют темперамент человека.
В психологии развития темперамент определяется как предрасположенность к той или иной реакции на внешние раздражители [38]. Темперамент определяется генетическими предпосылками и затем формируется в процессе взаимодействия с окружающей средой в течение всей жизни [39]. Нейроанатомические и психические предпосылки криминального принятия решений фактически обязаны своим существованием темпераменту. Темперамент обычно оценивается по критериям, два из которых особенно значимы для преступного поведения: это бесстрашие и отсутствие подавления [40]. Бесстрашие предполагает слабую выработку рефлекса страха, а отсутствие подавления влечет за собой слабый контроль над поведением. С точки зрения нейрофизиологии бесстрашие порождается гипофункцией лимбической системы в такой зоне мозга, как мозжечковая миндалина [41], а также слабой эмпатией и проактивным криминальным мышлением. В свою очередь, отсутствие подавления считается результатом гиперфункции полосатого тела мозга и гипофункцией гиппокампа [42], а также слабым контролем импульсов и реактивным криминальным мышлением. Исследования показывают, что низкая концентрация серого вещества в мозжечковой миндалине и гиппокампе коррелирует с бесстрашием и отсутствием подавления соответственно [43, в печати] и что проактивное криминальное мышление более тесно связано с бесстрашием, а реактивное - с отсутствием подавления [44]; однако аспекты психологии развития, связанные с этими категориями, до сих пор не получили должного исследования.

\section{Нравственные чувства и ожидания}

Как было показано выше, эмоции и соответствующие им области центральной нервной системы, занятые в появлении и подавлении эмоций (лимбические структуры и полосатое тело), влияют на процесс принятия решений через «телесную петлю» и «как бы телесную петлю», которые действуют в контексте психологии развития и могут считаться аспектами темперамента. Но как же все это превращается в решение? Мы считаем, что один из путей такого влияния эмоций на решения лежит через нравственные эмоции и ожидания. Ранее было установлено, что нравственные эмоции объединяют нравственные стандарты и нравственное поведение [45]. В этом случае под «нравственным» понимают то, что соответствует нравственным стандартам данной личности. То есть если человек 
придерживается нравственного стандарта «воровать нехорошо», но все равно ворует, то он чувствует вину и стыд. Если в конце концов его схватят и накажут, то чувство вины станет, возможно, еще сильнее, а понятие о том, что «воровать нехорошо», еще прочнее внедрится в его систему нравственных убеждений. Таким образом, именно нравственная эмоция фиксируется как положительная в случае принятия нравственного решения (гордость, эмпатия) и отрицательная в случае принятия безнравственного решения (вина, стыд).

Роль нравственных эмоций состоит в том, чтобы давать обратную связь о том, насколько данное решение соответствует нравственным стандартам. Для понимания того, как индивидуум действует под влиянием своих нравственных эмоций при принятии решения, нужно рассмотреть нравственные ожидания. Это ожидания того, что мы будем чувствовать, если нам придется воплотить то или иное решение в жизнь. Поскольку это ожидание предшествует решению, оно дает обратную связь по поводу того, насколько данное решение соответствует нашим нравственным стандартам [46]. Если я планирую что-то украсть и чувствую вину, страх или стыд от того, что подумают другие, то вероятность совершения кражи будет гораздо меньшей, независимо от возможности ее совершения или от силы соблазна. Krettenauer, Jia и Mosleh [47] провели эксперимент с участием 160 подростков и обнаружили, что нравственные ожидания влияют на процесс принятия решений как в антисоциальном, так и в просоциальном контекстах. В антисоциальном контексте негативные ожидания того, что индивидуум не способен действовать нравственно (вина), предопределили нравственный выбор. В просоциальном контексте позитивные ожидания успеха от своего нравственного поведения (гордость) предопределили нравственный выбор.

\section{Теория раџиионального и нераџионального выбора}

Используемый подход в некотором отношении связан с ранними работами Daniel Kahneman и Amos Tversky в области эвристики и когнитивных расстройств в процессе принятия решений $[48,49,50]$, однако наша работа посвящена криминальному принятию решения, что может отличаться или не отличаться от принятия повседневных решений. При разработке теории рационального и нерационального выбора и преступности мы попытались объединить самую, возможно, слабую сторону рациональной теории преступности - эмоции - с ее самой сильной стороной - утилитарным подходом. Первый уровень этой объединенной теории состоит из серии двунаправленных взаимоотношений между гедонистической и нравственной системами личности, а также решением и результатом. Второй уровень теории составляют гедонистические (например, гнев, удовольствие) и нравственные (например, вина, гордость) эмоции. Должным образом модулированные гедонистические эмоции дают информацию для принятия решений. Неверно модулированные гедонистические эмоции, напротив, нарушают утилитарный процесс принятия решений. Нравственные эмоции дают информацию для утилитарного процесса принятия решений, давая возможность нравственным стандартам оказывать влияние на решение. Третий уровень теории охватывает, с одной стороны, ситуационные, нейроанатомические факторы, а также факторы психологии развития и криминального мышления, которые стимулируют нерелевантные (для решения) гедонистические эмоции и, с другой стороны, ситуационные факторы, факторы психологии развития и криминального мышления, которые подавляют контекстуально релевантные нравственные эмоции.

На всех трех уровнях теории в данной статье мы рассматриваем влияние эмоциональных, когнитивных, нейропсихологических факторов и окружения на принятие решения, т. е. то, как личность действует под влиянием своих эмоций, стилей мышления, окружения и нейропсихологического контекста, принимая то или иное решение. Три уровня теории и их взаимодействие показаны на рис. 1. Для пояснения модели приведем пример индивидуума, недавно вышедшего из заключения, который раздумывает над возможностью ограбить банк. Назовем этого индивидуума Бобом.

\section{Система гедонистических убеждений}

Система гедонистических убеждений кодируется опытом получения вознаграждения и ассоциациями между внешними стимулами и прошлыми эмоциями. Она может рассматриваться как хранилище опыта получения вознаграждения или карта истории поощрений индивидуума. Значимость системы гедонистических убеждений для процесса принятия решений состоит в том, что она снабжает индивидуума информацией о той субъективной ценности, которую данный индивидуум придает различным вариантам выбора (т. е. выполняет эвристическую функцию). Система гедонистических убеждений

Уолтерс Г. Рациональность и нерациональность решения о совершении преступления

Walters G. D. Decision to commit crime: rational or nonrational 
тесно связана с богатым дофамином полосатым телом мозга и соответствующей ему вентральной тегментальной областью (ВТО), а также лимбической структурой, известной как гиппокамп. Допамин - это возбуждающий медиатор, который высвобождается в условиях возбуждения, удовольствия и вознаграждения. Таким образом, он дает обратную связь таким видам деятельности, которые приводят к вознаграждению. Должным образом модулированная рецепторами серотонина в гиппокампе и других отделах, эта информация положительным образом влияет на быстроту и эффективность принятия решений. При отсутствии модулирования система гедонистических убеждений может способствовать принятию рискованных решений и появлению временных расстройств. Как показано на рис. 1 двойными стрелками, система гедонистических убеждений определяет решения индивидуума и в свою очередь определяется ими и их результатами (петля обратной связи).

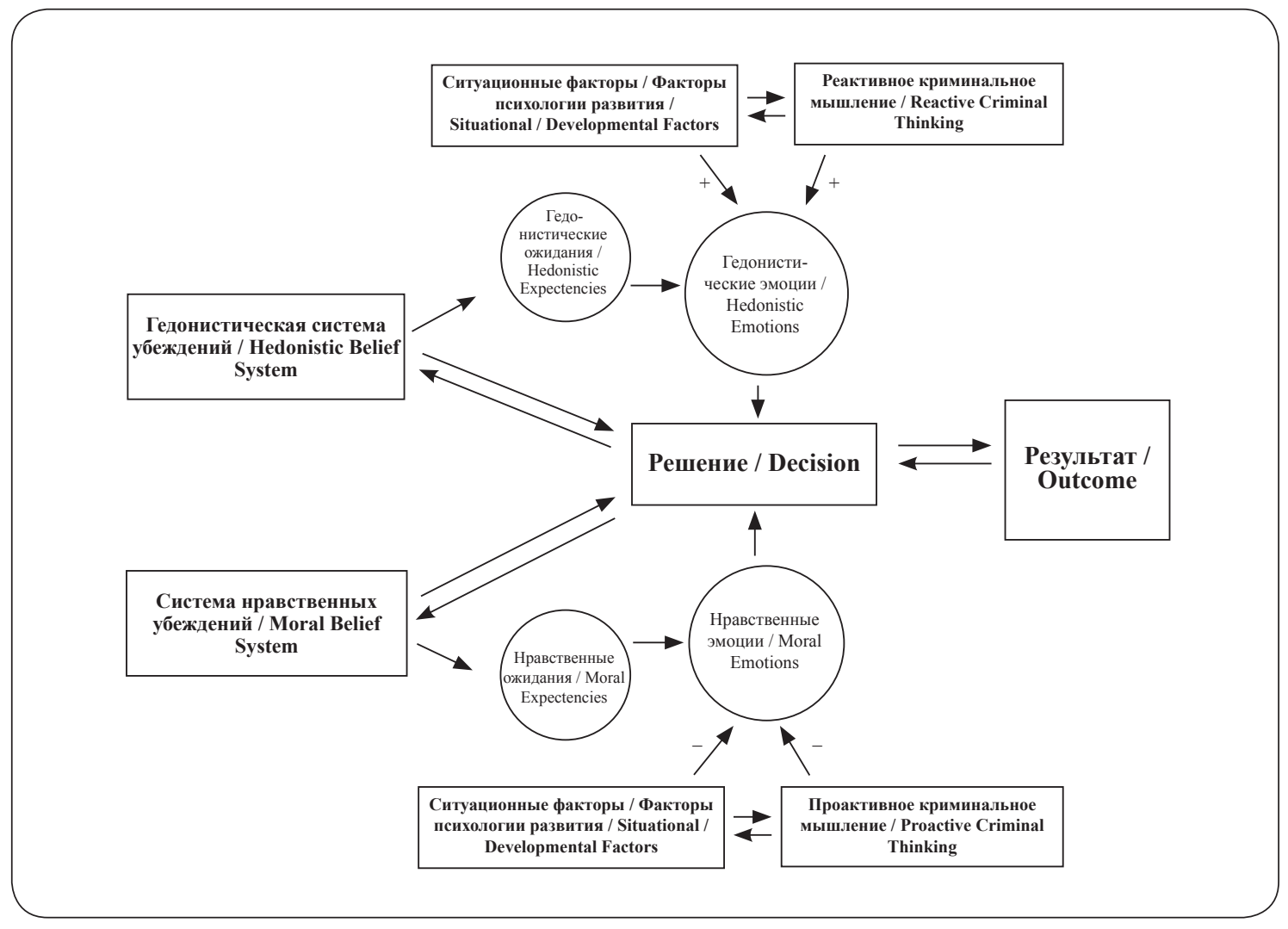

Рис. 1. Модель рационального и нерационального выбора

Прим. + = влияние, направленное на возбуждение; - = влияние, направленное на подавление.

Fig. 1. The Rational/Nonrational Choice Model

Note $+=$ excitatory influence; - = inhibitory influence.

Гедонистические эмоции. Гедонистические эмоции, такие как гнев, подавленность, настойчивость, возбуждение и удовольствие, требуют немедленного удовлетворения, концептуально следуя из системы гедонистических убеждений. Данные эмоции, требующие немедленных действий, считаются релевант- ными, когда они должным образом модулированы и скорее помогают, чем мешают процессу принятия решений. Гедонистические эмоции модулируются как когнитивными, так и нейрохимическими процессами. Они способствуют процессу принятия решений путем предоставления обратной связи на побудительные 
стимулы и события. Данные эмоции считаются нерелевантными, когда они немодулированы и мешают процессу принятия взвешенного и разумного решения. Ситуационные и эмоциональные факторы, если они не должным образом модулированы, мешают процессу принятия решений [51]. Изучив литературу по проблемам эмоций и решения задач, Angie, Connelly, Waples и Kligyte [52] приходят к выводу, что гнев часто способствует принятию рискованных решений, причем на противоположном полюсе находится чувство вины. Другими словами, гнев максимально нарушает процесс принятия решений, тогда как чувство вины дает нравственный ориентир, необходимый для принятия взвешенного решения.

Такие эмоции, как гнев, подавленность и возбуждение, часто вызываются или усиливаются ситуационными (стресс, присутствие наблюдателей) и когнитивными (реактивное криминальное мышление) факторами (см. рис. 1). Усиление эмоций - это лишь один из способов, которым эмоции влияют на процесс принятия решений; другим способом является уменьшение эмоционального воздействия, как показывает пример антиобщественной системы нравственных убеждений. Молодые люди, находящиеся под влиянием стресса или пытающиеся произвести впечатление на сверстников, более склонны к принятию рискованных решений, чем те, кто не находятся в такой ситуации. Реактивное криминальное мышление, в частности прекращение, вялость мышления и прерывность (см. табл. 1), может настолько усиливать гедонистические эмоции, такие как гнев, подавленность, стремление действовать, возбуждение, удовольствие, что они мешают способности индивидуума эффективно решать проблему. В табл. 2 перечислены три стиля реактивного криминального мышления и те эмоции, которые они, как правило, усиливают. Эти стили названы реактивными, потому что они побуждают индивидуума эмоционально реагировать на внешние раздражители в отличие от «хладнокровных» действий, вызываемых проактивным криминальным мышлением [40].

Импульсивность может быть вызвана слабостью самоконтроля или временным расстройством. Слабый самоконтроль подразумевает неосознавание последствий или неспособность заставить себя выбрать более крупное долгосрочное вознаграждение в обмен на более мелкое немедленное вознаграждение; временное расстройство означает невозможность учитывать отсроченные вознаграждения, несмотря на то, что они превышают немедленные вознаграждения [53]. Исследования показывают, что у преступников уровень временных расстройств выше, чем у не-преступников $[54,55]$. В соответствии с гипотезой, что реактивное криминальное мышление может мешать процессу принятия решений с помощью стимулирования нерелевантных эмоций, Varghese, Charlton, Wood, и Trower [56] провели исследование в группе из 146 мужчин за пять месяцев до освобождения из мест лишения свободы и обнаружили, что временное расстройство коррелирует с реактивным криминальным мышлением, но не коррелирует с проактивным криминальным мышлением.

Рассмотрим действие системы гедонистических принципов на примере Боба, индивидуума, недавно вышедшего из заключения, который раздумывает над возможностью ограбить банк. Боб не имеет семьи, за исключением брата, который живет в другом штате; его друзья - это старые криминальные партнеры и те, с кем он познакомился в тюрьме. Боб сделал пару не очень настойчивых попыток найти работу, но у него ничего не вышло, и он прекратил искать законный заработок. В настоящее время Боб подавлен, он находится в состоянии гнева и отчаяния. Кроме того, он испытывает высокий уровень гедонистических эмоций как в позитивной (предвкушение возбуждения от совершения нового преступления), так и в негативной форме (гнев и подавленность), его мышление характеризуется отрывистостью и непостоянством. Соответственно, его решения будут далеко не оптимальны, поскольку он действует под влиянием гедонистических эмоций, которые нарушают его суждения.

\section{Система нравственных убеждений}

Система нравственных убеждений складывается из стандартов, норм, ценностей и тех элементов мировоззрения человека, которые имеют отношение к нравственности, например, это осознанные оценки и понятие о справедливости. Как и система гедонистических убеждений, она находится в тесной и взаимной связи с решениями и их последствиями. Долгосрочная вовлеченность в криминальную деятельность может привести к укреплению системы 
нравственных убеждений и последующего принятия решений о совершении преступлений. Фактически именно поэтому, в частности, принимаются криминальные решения. Индивидуумы с антиобщественной системой нравственных убеждений враждебны по отношению к обществу и часто выбирают криминальный путь потому, что преступление противоречит общепринятому общественному порядку. При этом, однако, большинство преступников не разделяют в полной мере систему антиобщественных нравственных убеждений, учитывая ту частоту, с которой множество преступников пользуются нейтрализацией для избавления от чувства вины и оправдания своей преступной деятельности $[57,58]$. Это означает, что основная часть преступности объясняется другими причинами.

Нравственные эмоции. В то время как гедонистические эмоции способствуют процессу принятия криминальных решений в силу самого своего существования, наполняя индивидуума нерелевантными эмоциями, требующими немедленных действий, нравственные эмоции способствуют процессу принятия криминальных решений при их отсутствии. Нейтрализация [58] нравственных эмоций приводит к чисто рациональному выбору при минимальном содействии системы нравственных убеждений. Поэтому индивидуум действует исключительно на основе рациональных соображений, при минимальном вкладе со стороны нерациональных источников информации (например, эмпатии, сострадания). Когда нравственные эмоции исключены из расчета при принятии решений, остается только хладнокровное решение, свободное от любых моральных соображений. В таком случае нет ничего плохого или хорошего, только целесообразное. Хороший пример подобного процесса приводит Earley [59] в своей книги о жизни в федеральной тюрьме Ливенворт. Герой книги, заключенный по имени Карл Боулз, хладнокровно рассказывает, как, сбежав из тюрьмы и чуть не убив агента ФБР, он похитил пожилую пару, украл их автомобиль, вывез их в пустынную местность и убил, только чтобы выиграть несколько лишних часов на свободе. Это было холодным и взвешенным решением, без каких-либо эмоций или морального выбора, которые определяют обдуманное решение. При этом он посчитал необходимым сообщить пожилой паре, перед тем как убил их, что он не испытывает к ним никакой враждебности и надеется, что они также не испытывают к нему отрицательных чувств.

Если реактивное криминальное мышление мешает процессу принятия решений, стимулируя нерелевантные эмоции, то проактивное криминальное мышление (см. табл. 1) мешает процессу принятия решений, подавляя релевантные эмоции. Очевидно, что всякий проактивный стиль мышления способен нейтрализовать свою область нравственных эмоций. Так, умиротворение уменьшает, прежде всего, чувство вины и угрызения совести, ощущение собственной правоты лучше всего нейтрализует эмпатию, авторитарность нейтрализует стыд, а сверхоптимистичность - гордость и страх (см. табл. 2).

Таблица 1

Описание девяти стилей мышления*

Table 1. Descriptions of the Nine Thinking Styles*

\begin{tabular}{|c|c|}
\hline $\begin{array}{c}\text { Стиль мышления / } \\
\text { Thinking Style }\end{array}$ & $\begin{array}{l}\text { Описание / } \\
\text { Description }\end{array}$ \\
\hline $\begin{array}{l}\text { Реактивный / } \\
\text { Reactive }\end{array}$ & $\begin{array}{l}\text { Импульсивный, спонтанный, безрассудный, эмоцио- } \\
\text { нальный подход / Impulsive, spontaneous, reckless, and } \\
\text { hot-blooded cognitive approach }\end{array}$ \\
\hline $\begin{array}{l}\text { Прекращение / } \\
\text { Cutoff }\end{array}$ & $\begin{array}{l}\text { Быстрое переключение из-за одного слова или фразы } \\
\text { / Rapid elimination of deterrents through a single word or } \\
\text { phrase }\end{array}$ \\
\hline $\begin{array}{l}\text { Вялость мышления / } \\
\text { Cognitive Indolence }\end{array}$ & $\begin{array}{l}\text { Ленивое и бессистемное мышление, недостаток крити- } \\
\text { ческого рассуждения / Lazy and haphazard thinking and } \\
\text { general lack of critical reasoning }\end{array}$ \\
\hline $\begin{array}{l}\text { Прерывность / } \\
\text { Discontinuity }\end{array}$ & $\begin{array}{l}\text { Неспособность придерживаться целей и планов; недо- } \\
\text { статок настойчивости / Failure to follow-through on goals } \\
\text { and plans; lack of consistency }\end{array}$ \\
\hline $\begin{array}{l}\text { Проактивный / } \\
\text { Proactive }\end{array}$ & $\begin{array}{l}\text { Планирование, разработка, хладнокровный когнитив- } \\
\text { ный подход / Planning, plotting, scheming, and cold- } \\
\text { blooded cognitive approach }\end{array}$ \\
\hline $\begin{array}{l}\text { Умиротворение / } \\
\text { Mollification }\end{array}$ & $\begin{array}{l}\text { Перенос вины за собственные действия на внешние } \\
\text { факторы / Externalizing blame for own actions onto outside } \\
\text { forces }\end{array}$ \\
\hline $\begin{array}{l}\text { Ощущение соб- } \\
\text { ственной правоты / } \\
\text { Entitlement }\end{array}$ & $\begin{array}{l}\text { Разрешение самому себе совершить преступление по } \\
\text { привилегии/необходимости / Giving oneself permission to } \\
\text { commit crime out of privilege/necessity }\end{array}$ \\
\hline $\begin{array}{l}\text { Властность / Power } \\
\text { Orientation }\end{array}$ & $\begin{array}{l}\text { Желание контролировать внешние факторы, включая } \\
\text { других людей / Desire to control external factors, including } \\
\text { other people }\end{array}$ \\
\hline $\begin{array}{l}\text { Сверхопти- } \\
\text { мистичность / } \\
\text { Superoptimism }\end{array}$ & $\begin{array}{l}\text { Чрезмерная гордость и вера в свою неуязвимость } \\
\text { / Excessive pride in oneself and belief in lasting } \\
\text { invulnerability }\end{array}$ \\
\hline
\end{tabular}

* Источник: [40].

* Source: [40]. 
Таблица 2

Возбуждающее и подавляющее воздействие криминального мышления на эмоции

Table 2. Excitatory and Inhibitory Effects of Criminal Thinking on Emotion

\begin{tabular}{|c|c|c|c|c|}
\hline $\begin{array}{c}\text { Стиль } \\
\text { мышления / } \\
\text { Thinking Style } \\
\end{array}$ & $\begin{array}{l}\text { Эмоция / } \\
\text { Emotion }\end{array}$ & $\begin{array}{c}\text { Результат } \\
\text { Effect }\end{array}$ & $\begin{array}{c}\text { Темперамент / } \\
\text { Temperament }\end{array}$ & $\begin{array}{l}\text { Действие / } \\
\text { Action }\end{array}$ \\
\hline $\begin{array}{l}\text { Реактивный / } \\
\text { Reactive }\end{array}$ & $\begin{array}{l}\text { Гедонистические / } \\
\text { Hedonistic }\end{array}$ & + & $\begin{array}{l}\text { Отсутствие } \\
\text { подавления / } \\
\text { Disinhibition }\end{array}$ & \\
\hline $\begin{array}{c}\text { Прекращение / } \\
\text { Cutoff }\end{array}$ & & & & $\begin{array}{l}\uparrow \text { подавленность } \\
\text { / frustration } \\
\uparrow \text { гнев / anger }\end{array}$ \\
\hline $\begin{array}{c}\text { Вялость } \\
\text { мышления / } \\
\text { Cognitive } \\
\text { Indolence }\end{array}$ & & & & $\begin{array}{l}\uparrow \text { стремление } \\
\text { действовать / } \\
\text { urgency }\end{array}$ \\
\hline $\begin{array}{c}\text { Прерывность / } \\
\text { Discontinuity }\end{array}$ & & & & 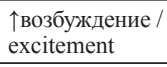 \\
\hline $\begin{array}{c}\text { Проактивный / } \\
\text { Proactive }\end{array}$ & $\begin{array}{c}\text { Нравственные / } \\
\text { Moral } \\
\end{array}$ & - & $\begin{array}{l}\text { Бесстрашие / } \\
\text { Fearlessness } \\
\end{array}$ & \\
\hline $\begin{array}{l}\text { Умиротворение / } \\
\text { Mollification }\end{array}$ & & & & $\begin{array}{l}\downarrow \text { вина / guilt } \\
\downarrow \text { угрызения } \\
\text { совести / } \\
\text { remorse }\end{array}$ \\
\hline $\begin{array}{c}\text { Ощущение } \\
\text { собственной } \\
\text { правоты / } \\
\text { Entitlement }\end{array}$ & & & & $\begin{array}{l}\downarrow \text { эмпатия / } \\
\text { empathy }\end{array}$ \\
\hline $\begin{array}{c}\text { Властность / } \\
\text { Power } \\
\text { Orientation } \\
\end{array}$ & & & & $\downarrow$ стыд /shame \\
\hline $\begin{array}{l}\text { Сверхопти- } \\
\text { мистичность / } \\
\text { Superoptimism }\end{array}$ & & & & $\begin{array}{l}\downarrow \text { гордость / } \\
\text { pride } \\
\downarrow \text { страх / fear }\end{array}$ \\
\hline
\end{tabular}

Прим. Стиль мылиления = высшего порядка (реактивный или проактивный) и отдельные стили низшего порядка [40]; эмоция = эмоция, на которую воздействует стиль мышления (гедонистическая или нравственная); результат = воздействие стиля мыпиения на соответствуюшую эмоцию $(+=$ возбуждающее - - =одавляющее); темперамент = темперамент которым определяется стиль мылиления (отсутствие подавления или бесстрашие); действие = особая эмочия, которую вызывает стиль мышления ( $\uparrow=$ повыпает, $\downarrow=$ понижает).

Note. Thinking Style $=$ higher-order (Reactive or Proactive) and specific lower-order thinking style [40]; Emotion = emotion that the thinking style targets (hedonistic or moral); Effect = effect of thinking style on targeted emotion ( $+=$ excitatory or $-=$ inhibitory); Temperament $=$ temperament dimension the thinking style derives from (disinhibition or fearlessness); Action = specific emotion each thinking style effects $(\uparrow=$ raises, $\downarrow=$ lowers).

Когда человек решает совершить нечто противоречащее его системе нравственных убеждений, он использует тот или иной стиль мышления, чтобы подавить нравственную эмоцию и тем самым уменьшить, если не полностью уничтожить, конфликт. Будь то совершение преступления самим индивидуумом или его донос на другого преступника, механизм оста- ется тем же: подавление нравственной эмоции (вина, стыд, гордость) с помощью одного или нескольких проактивно криминальных стилей мышления. Ситуационные факторы, угрожающие статусу или личности индивидуума, также могут служить толчком для подавления нравственных эмоций; факторы нейропсихического развития, которые затрудняют понимание чувств других людей (слабая эмпатия и предвидение), также способствуют процессу нейтрализации.

Когда нравственные эмоции уничтожены, остается лишь утилитарное решение - совершать или не совершать преступление. Итак, подавляя релевантные нравственные эмоции с помощью проактивных криминальных стилей мышления, мы приходим к ситуации, когда рациональный выбор не является оптимальным. Психопатические убийцы часто используют хладнокровную логику, принимая решение об убийстве, что значительно отличается от импульсивных убийств, наблюдаемых у не-психопатических преступников [60]. Кроме того, Beauregard, Rossmo и Proulx [61] использовали ТРВ для анализа криминальных действий 69 серийных сексуальных преступников. Используя качественный анализ, они обнаружили, что поведение при преследовании и нападении, демонстрируемое такими преступниками, проходило девять этапов, каждый из которых включал особые расчеты соотношения затрат и выгод: повседневная деятельность преступника и жертвы, выбор места для преследования, выбор жертвы, место нападения, стратегия приманивания, место преступления, способ совершения преступления, место освобождения жертвы. Отсюда следует, что если эмоции при принятии решения неожиданно уменьшаются или исчезают, то утилитарный метод, используемый в ТРВ, все равно недостаточен.

Подавленность Боба не только способствовала появлению гедонистических эмоций, но и стимулировала проактивное криминальное мышление. В частности, он ощущает себя вправе ограбить банк, потому что предыдущее заключение было таким долгим («Они закрыли меня на десять лет, теперь они заплатят за это»). Он приводит рациональные аргументы, что никому не причинит зла («Я возьму незаряженное ружье»), и наслаждается мыслью о власти над окружающими («Я им покажу, кто главный»). Следовательно, нейтрализация нравственных эмоций происходит с помощью ощущения собственной правоты, умиротворения и стремления к власти. Это повышает вероятность того, что Боб выполнит 
свой первоначальный план по ограблению банка. Следует также отметить, что системы гедонистических и нравственных убеждений независимы не в большей степени, чем бесстрашие, отсутствие подавления или проактивное и реактивное криминальное мышление [40]. Два компонента накладываются и подпитывают друг друга, и часто можно наблюдать, как один из компонентов стимулирует и активирует другой.

\section{Прочесс принятия решения}

Исходная предпосылка данной статьи состоит в том, что решение о совершении или несовершении преступления начинается с анализа затрат и выгод, но для полной реализации своей функциональности требует наличия релевантной эмоциональной информации и обратной связи. Соответственно, нейтрализация нравственной информации делает процесс принятия решения менее сбалансированным, как и введение нерелевантной гедонистической эмоции. Как показано на рис. 1, гедонистические и нравственные эмоции воспринимаются еще до принятия решения посредством гедонистических и нравственных ожиданий. Роль аффективных ожиданий в принятии решений была показана в работах Loewenstein и Lerner [46], которые пришли к выводу, что такие ожидания являются ключевыми в процессе принятия решений. На эти эмоции, в свою очередь, воздействуют, при их наличии, ситуационные факторы и факторы нейропсихического развития, а также стили криминального мышления, хотя точнее было бы сказать, что индивидуум действует под влиянием этих эмоций через ситуационные/нейропсихические факторы и криминальное мышление. Влияние ситуационных/нейропсихических факторов на гедонистические и нравственные эмоции может быть явным или скрытым, а влияние стиля криминального мышления на гедонистические и нравственные эмоции может быть осознанным (намеренным) или подсознательным (автоматическим). В нашем примере с ограблением банка решение Боба было принято под влиянием ситуационных факторов (подавленность из-за неудач в поиске работы), нейропсихических факторов (слабая эмпатия) и сочетания проактивного (ощущение собственной правоты, умиротворение и стремление к власти) и реактивного (прекращение, прерывность) стилей криминального мышления.

Рассматривая модель рационального/нерационального выбора, важно понимать, что проактивный и реактивный стили криминального мышления действуют скорее как перекрывающие друг друга, чем как независимые друг от друга категории. Это происходит потому, что проактивный и реактивный стили криминального мышления часто сосуществуют даже в рамках одного криминального акта. Боб решил ограбить местный банк после того, как несколько дней колебался между умеренно антиобщественной системой нравственных убеждений и достаточно сильным проактивным криминальным мышлением. В процессе ограбления он почувствовал гнев, так как сотрудница банка недостаточно быстро передала ему деньги. Это привело к насильственным действиям (он ударил женщину рукояткой пистолета) под влиянием реактивного криминального мышления и нерелевантной гедонистической эмоции. Это преступление начиналось с хладнокровного утилитарного решения о грабеже, а затем превратилось в насильственное преступление, основанное на импульсивном решении, вызванном эмоциями. Ситуационные и нейропсихические факторы также перекрываются, например, влияние окружения может стимулировать гедонистические эмоции (возбуждение), при этом подавляя нравственные (желание быть принятым в группу).

Два индивидуума, вместе с которыми Боб решил ограбить банк, были еще более заинтересованы в этом преступлении, чем Боб, и подталкивали его к более решительным действиям. Стимуляция гедонистического желания испытать возбуждение привела к подавлению нравственных и утилитарных соображений о том, что нужно подождать более подходящего времени для ограбления, потому что он стремился к признанию со стороны этих индивидуумов. Изначально само желание совершить преступление и воспользоваться его плодами (10 тысяч долларов на троих плюс возбуждение от ощущения власти) запустило процесс мышления, которое привело к решению, в свою очередь повысившему вероятность повторного совершения преступления. Фактически Боб и два его подельника совершили еще одно ограбление три недели спустя, но на этот раз их задержали.

\section{Гипотезы}

Большая часть материалов данной статьи не подвергалась формальной проверке. Для проверки модели рационального/нерационального выбора при принятии криминального решения мы построили ряд гипотез. Эти гипотезы призваны задать направление будущим исследованиям и выявить те аспекты 
модели, которые следует сохранить, отвергнуть или изменить для достижения более глубокого объяснения преступности, чем предлагает традиционная ТРВ.

1. Между системами гедонистических и нравственных убеждений, с одной стороны, и решением совершить преступление и результатом этого решения, с другой, существуют двусторонние отношения такого рода, что обратная связь от принятых решений и их результатов формирует системы убеждений в такой же степени, что и системы убеждений решений и их результатов формируют решения и их результаты. Отсюда следует, что если человек вынужден принять решение, несовместимое с его системами гедонистических и нравственных убеждений, то это повлечет за собой изменения в данных системах (когнитивный диссонанс).

2. Будучи помещенным в стрессовую ситуацию или находясь в стесненных обстоятельствах, индивидуум будет более склонен к принятию рискованных решений и проявлению временных расстройств, чем в отсутствие таких обстоятельств.

3. Индивидуум, достигший высокого уровня реактивного криминального мышления, будет более склонен к принятию рискованных решений и проявлению временных расстройств, чем индивидуум, не достигший высокого уровня реактивного криминального мышления.

4. Под влиянием событий, которые ставят под угрозу статус или личностную идентификацию (например, появление неуважения), индивидуум будет проявлять более слабые нравственные эмоции, чем в отсутствие таких событий.

5. Индивидуум, достигший высокого уровня проактивного криминального мышления, будет проявлять более слабые нравственные эмоции, чем индивидуум, не достигший высокого уровня проактивного криминального мышления.

6. В порядке эксперимента изменяя гедонистические ожидания, мы будем наблюдать изменения гедонистических эмоций и решений, а изменяя в порядке эксперимента нравственные ожидания, мы будем наблюдать изменения нравственных эмоций и решений.

7. Усиление реактивного криминального мышления будет коррелировать положительно с допаминергической активностью в вентральной тегментальной области (BТО) и полосатом теле головного мозга и отрицательно - с серотонинергической активностью в гиппокампе.

8. Усиление проактивного криминального мышления будет коррелировать отрицательно с активностью в лобной коре (ЛК) и мозжечковой миндалине головного мозга и отрицательно - с уровнем серотонина в обеих данных областях.

9. Поскольку нейропобудительные системы развиваются быстрее, чем нейроконтролирующие, гедонистические эмоции будут наблюдаться раньше в процессе психического развития, чем нравственные эмоции, а реактивные формы криминального мышления появятся раньше, чем проактивные.

10. Индивидуумы, прошедшие как обучение навыкам (решение межличностных проблем, управление гневом), так и нравственную подготовку (осознание ценностей, повышение нравственного уровня), будут демонстрировать существенно более низкие уровни рецидивизма, чем индивидуумы, прошедшие лишь один какой-либо вид обучения.

Сравнение категорий реактивности и проактивности в прочессе принятия криминальных решений

Основная идея данной теоретической модели состоит в том, что проактивное и реактивное криминальное мышление вносят равный вклад в процесс принятия криминального решения, хотя относятся к разным аспектам этого процесса. Следовательно, хотя известно, что проактивное криминальное мышление нейтрализует нравственные эмоции, а реактивное стимулирует гедонистические эмоции, оба они являются центральными элементами аппарата принятия криминального решения. Проактивное криминальное мышление поддерживает аспекты «хищника», планируемые, хладнокровные аспекты преступности, тогда как реактивное криминальное мышление усиливает аспекты гнева, импульсивности, аффективной преступности. Значимость этих дополняющих друг друга измерений процесса принятия криминального решения может быть наилучшим образом проиллюстрирована путем сравнения предлагаемого подхода с теоретическими моделями, фокусирующимися на том или другом измерении.

Общая теория преступности, предложенная Gottfredson и Hirschi [6], предлагает исключительно реактивную интерпретацию криминального принятия решений. Согласно этой теории, криминальное принятие решений есть функция двух факторов: низкого самоконтроля и наличия возможности совершить преступление. Предполагается, что индивидуум с низким уровнем самоконтроля, которому представилась возможность совершить преступление, с большой степенью вероятности совершит его. Хотя данная теория

Уолтерс Г. Рациональность и нерациональность решения о совершении преступления

Walters G. D. Decision to commit crime: rational or nonrational 
помогла пролить свет на ряд важнейших аспектов преступности, она не учитывает, что многие преступники сознательно ищут и создают возможность для совершения преступлений, а не ждут, когда она появится [62]. Это одна из причин, почему данную теорию нельзя считать настолько общей, как заявляют ее авторы.

Tedeschi и Felson [5] предлагают другой подход к проблеме криминального принятия решений, согласно которому все правонарушения либо преследуют конкретную цель, либо являются инструментом для достижения конкретного результата; другими словами, преступность является исключительно проактивной. Ранеe Felson [63] отрицал разделение на реактивную и проактивную агрессию, вместо этого говоря о поведении «спорщика» и «хищника». Ценность такого подхода в том, что он показывает, что преступления, долгое время считавшиеся импульсивными (например, домашнее насилие), могут быть инструментальными или планируемыми, по крайней мере частично. Однако этот подход не учитывает того факта, что большинство преступников указывают на отсутствие планирования своих преступлений $[64,65]$. Согласно исследованиям самого Felson'a, большинство отбывающих наказание за тяжкие преступления утверждают, что их преступления не были запланированы, планирование же встречается в основном в традиционно «инструментальных» преступлениях, таких как грабеж, а не в традиционно импульсивных, таких как изнасилование [66].

Подход, использованный в данной статье, предлагает сочетание двух описанных выше подходов: исключительно реактивного криминального мышления, присущего общей теории преступности, и исключительно проактивного криминального мышления, которое предлагает теория социального взаимодействия. Gottfredson и Hirschi [6] считают, что в процессе принятия криминального решения существенно наличие возможности, однако они не учитывают, что иногда преступники сами создают эти возможности. Tedeschi и Felson [5] признают, что процесс принятия криминального решения опосредуется когнитивными свойствами, но не учитывают, что при этом может быть задействован не только когнитивный процесс. Традиционный подход, концентрирующийся на самом преступлении и классифицирующий преступное поведение как проактивное/импульсивное или реактивное/импульсивное, не может считаться правильным, так как большинство преступлений со- четают в себе оба этих аспекта. Более целесообразным было бы рассматривать рациональные и нерациональные аспекты процесса принятия криминального решения, начиная от проактивного или реактивного криминального мышления и заканчивая его реализацией в криминальном поведении.

Следствия из теории рациинального/нерационального выбора при совершении преступления

Теория рационального/нерационального выбора имеет важные следствия для теоретического изучения, исследований, практики и политики.

\section{Следствия для теоретического изучения и исследований}

Данная модель базируется на сильных сторонах ТРВ, пытаясь при этом преодолеть ее слабые стороны. Сильные стороны ТРВ включают: положение, что преступление определяется в большей степени внутренними факторами принятия решений, чем внешними факторами окружающей среды, и что рациональность присутствует при принятии решений как криминального, так и некриминального характера. Принципиально слабая сторона ТРВ, как показано в данной статье, состоит в том, что, хотя ее сторонники и признают ограниченность рационального мышления, это не нашло явного отражения в теории. Согласно подходу, предлагаемому в данной статье, процесс принятия криминального решения сочетает в себе как рациональные, так и нерациональные элементы, которые формируются под влиянием как внешних, так и внутренних факторов. Мы также рассматриваем, как ситуационные, нейропсихические факторы и факторы криминального мышления оказывают значительное влияние на процесс принятия криминального решения. Таким образом, модель рационального/нерационального выбора может иметь следствия, существенные для ряда криминологических теорий, основанных на концепции принятия решений, которые упоминались в начале данной статьи. Также наша модель подкрепляет теорию устрашения, поскольку придает большое значение субъективности и подчеркивает, что реакция индивидуума на наказание определяется не столько его суровостью, сколько именно отношением данного индивидуума к наказанию; мы также считаем, что некоторые аспекты теории устрашения (например, суровость наказания) являются более субъективными, чем другие (например, определенность наказания). Этим можно объяснить, почему устрашение относит- 
ся в большей степени к тем преступлениям, за которые индивидуум уже бывал наказан, и почему суровость наказания менее эффективна в предотвращении будущих преступлений, чем определенность наказания [67]. Данную модель можно также применить для объяснения аспектов проактивности/«аспектов хищника» в теории рутинных действий [61] и аспектов реактивности/импульсивности в общей теории преступности Gottfredson и Hirschi [6].

Еще одним теоретическим/исследовательским следствием модели рационального/нерационального выбора является то, что она может дать ценную информацию о природе и роли черт «равнодушия/ безэмоциональности» при нарушениях поведения у детей, преступности несовершеннолетних и антиобщественном поведении взрослых. Черты «равнодушия/безэмоциональности» (синдром Р/Б) являются основной темой исследований и теоретических работ в сфере психопатологии и агрессии. Кроме того, они включены в 5-е издание Диагностического и статистического руководства по психическим расстройствам (DSM-5 - The Diagnostic and Statistical Manual of Mental Disorders) [68] в качестве признаков нарушений поведения, поскольку считается, что дети с нарушениями поведения в сочетании с Р/Б показывают гораздо худшие результаты лечения, чем без данного синдрома [69]. Существует также мнение, что Р/Б это наследуемый признак, которое доказывается на основе исследований близнецов, хотя исследования на основе ДНК не дают столь твердой уверенности [70]. Модель рационального/нерационального выбора, напротив, предполагает, что синдром Р/Б может быть как функцией ситуативных и когнитивных (проактивное криминальное мышление) факторов, так и генетических (гипофункция мозжечковой миндалины и раннее проявление черт бесстрашия в темпераменте), а следовательно, может быть сильнее подвержен коррекции, чем традиционно считается. Mulvey [71] изучал соотношение между уровнем Р/Б по шкале «Психопатические черты у молодежи» (Youth Psychopathic Traits Inventory (YPI) [72] и уровнем преступности. Было проведено шесть серий исследований в рамках программы «Pathways to Desistance» (с шестимесячным перерывом между сериями), и обнаружено, что, хотя внутри каждого шестимесячного интервала уровень Р/Б был более устойчив, чем уровень преступности (в среднем $r=0,57$ и 0,45 соответственно), перекрестные корреляции между влиянием уровня преступно- сти на Р/Б и Р/Б на уровень преступности оказались практически одинаковыми (в среднем $r=0,25$ и 0,24 соответственно). Это означает, что уровень преступности может иметь такое же влияние на Р/Б (эффект десенсибилизации), как и наоборот, Р/Б на уровень преступности (эффект наказания).

Третье теоретическое/исследовательское следствие модели рационального/нерационального выбора состоит в том, что она может объяснить широко известную, но не получившую достаточного обоснования корреляцию между возрастом и преступностью. Как перекрестные, так и лонгитюдные исследования данной корреляции показывают, что пик преступности приходится на возраст между подростковым и ранним взрослым периодом (от 15 до 24 лет) и затем резко падает [73]. Hirschi и Gottfredson [74] утверждают, что данная корреляция является непреложным фактом криминологии и не зависит от временных, географических, культурных и других факторов, рассматриваемых в криминологии. Хотя это утверждение оспаривалось [75], данную корреляцию редко объясняют иначе, чем биологическими особенностями развития [76]. Возрастные различия между подростками и взрослыми как в области нейрофизиологии, так и в области принятия решений могут объяснить данный факт. Поскольку допаминовая система вознаграждения, частью которой является полосатое тело мозга, развивается быстрее, чем центры контроля лобной коры, подросток вынужден справляться с более сильными нерелевантными гедонистическими эмоциями, чем взрослый [24], а поскольку навыки и склонности, ключевые для развития эмпатии (аффективный компонент теории психики), находятся все еще в процессе развития со среднего до старшего подросткового возраста, то релевантные нравственные эмоции у подростков слабее, чем у взрослых [28]. Положение усугубляют ситуационные факторы, которые имеют большое значение в подростковом возрасте (например, мнение сверстников, формирование личности). Следовательно, индивидуум должен сократить или совсем прекратить свою преступную деятельность, так как, став взрослым, он будет подругому смотреть на себя и окружающий мир.

\section{Практические следствия}

Хорошо известно, с какими проблемами сталкиваются подростки, пытаясь не дать своим нерелевантным гедонистическим эмоциям влиять на мышление и принятие решений. Чем же вызваны эти проблемы?

Уолтерс Г. Рациональность и нерациональность решения о совершении преступления

Walters G. D. Decision to commit crime: rational or nonrational 
Исследования показывают, что у подростков стремление достичь желаемого развивается быстрее, чем способность сдерживать свои желания и связанные с ними гедонистические эмоции [33]. Выявлено также, что систему желания/вознаграждения запускает допамин, тогда как серотонин модулирует влияние допамина на поведение [77]. Таким образом, очевидно, что вещества, повышающие уровень или усиливающие воздействие серотонина на рецепторы, способствуют контролю над импульсивным поведением. Это подтверждено рядом исследований. Хотя результаты еще не окончательные, было обнаружено, что вещества из группы Specific Serotonin Reuptake Inhibitors (SSRI), т. е. ингибиторы повторного поглощения серотонина, входящие в состав некоторых лекарственных средств (например, Prozac, Paxil, Zoloft), снижают импульсивность и агрессивность поведения у преступников и психиатрических больных [78, 79]. Хорошо задокументированы и побочные эффекты этих веществ, например акатизия и беспокойство, хотя они встречаются нечасто [80]. В популярных изданиях сообщалось и о более серьезных реакциях, вплоть до убийств и самоубийств, но такие случаи не документированы, а сообщения основывались лишь на слухах и изучении клинических случаев постфактум, а не на научных исследованиях с использованием плацебо и двойного слепого метода [79]. И все же производители лекарств теперь рекомендуют пристальное наблюдение за подростками, принимающими лекарства из группы SSRI от депрессии или агрессии, особенно в начальный период приема лекарства.

Медикаментозное лечение не единственный способ помочь подростку справиться с высоким уровнем гедонистических эмоций. Психологическая помощь может быть настолько же, если не более, эффективной для снижения чрезмерного уровня гедонистических эмоций, агрессии и антиобщественного поведения. Тренинги по решению межличностных проблем, управлению гневом и развитию общественных навыков эффективны для снижения импульсивности, агрессивности и преступности среди молодежи [81]. Однако следует отметить, что, применяя принципы ТРВ при обучении молодежи, мы решаем лишь часть проблемы. Исследуя взрослых мужчин, совершивших преступления средней степени тяжести, прошедших шестимесячный тренинг по управлению гневом, Walters [82] обнаружил, что такие тренинги снижали реактивное, но не проактивное криминальное мыш- ление. Методики, призванные научить подростков контролировать гедонистические эмоции, могут непреднамеренно развить в них безэмоциональность, равнодушие. Чтобы избежать этого, следует не отказываться от обучения преступников навыкам решения проблем и управления гневом, а дополнить эти тренинги качественными практическими программами по развитию когнитивно-нравственных навыков, осознанию ценностей, повышению нравственного уровня [83], а также навыков эмпатии через ролевые игры [84]. С помощью таких мер гедонистические эмоции могут быть модулированы, а нравственные эффективно интегрированы в процесс принятия решений, что снизит вероятность криминального решения.

\section{Политические следствия}

То, что криминальное решение включает нерациональные элементы, не означает, что индивидуум освобождается от ответственности за такое решение. Как с юридической, так и с этической точки зрения индивидуум несет ответственность за свои решения независимо от того, основаны они на рациональных, нерациональных соображениях или на тех и других вместе взятых. Модель рационального/нерационального принятия криминальных решений, описанная в данной статье, отражает не-детерминистскую точку зрения на поведение человека и объясняет, каким образом криминальное мышление влияет на поведение через процесс принятия решений. Ситуационные, психические и биологические факторы влияют на поведение человека, но индивидуум отвечает за последствия всех принимаемых им решений, если только психическое или физическое расстройство не препятствует пониманию им последствий своих действий. С политической точки зрения правовая система основывается на понятии выбора, а не детерминизма, даже если этот выбор не является рациональным с точки зрения ТРВ.

Многочисленные примеры говорят о том, что усиление суровости наказания редко приносит ожидаемые результаты [85]. Тем не менее политики и законодатели по-прежнему прибегают к этому упрощенному подходу к предотвращению преступности. Ситуативные методы профилактики преступности направлены в большей степени на внешние, чем на внутренние взаимоотношения между компонентами преступления; этот подход получает подкрепление в теориях, придающих важное значение аффекту и эмоциям, как это изложено в данной статье. Ситуативная 
профилактика преступности может работать лучше, если с помощью средств массовой информации и социальной рекламы усиливать у преступников чувство вины, тем самым уменьшая чувство удовлетворения от совершения преступления. Такая стратегия контроля преступности находит признание у все большего числа законодателей [86]. Pratt [87] утверждает, что криминологи и эксперты в области криминального правосудия должны представлять результаты своих исследований в форме, более пригодной для практического использования законодателями. Например, он рекомендует писать исследования более доступным языком и подчеркивать и объяснять значимость результатов исследований для политиков, руководящих работников и законодателей в сфере общественного порядка.

\section{Выводы}

Данная статья знакомит читателя с комбинированной моделью процесса принятия решений, объединяющей рациональные и нерациональные компоненты выбора. В начале статьи отмечалось, что ТРВ объясняет сущность преступности, но имеет ряд значительных ограничений. Одно из таких ограничений (недостаток внимания к аффективным и эмоциональным компонентам криминального принятия решений) послужило главной темой данной работы и стало основой для построения теории рациональности/нерациональности при криминальном принятии решений. Гедонистический аспект данной модели рассматривает выгоды от совершения конкретного действия, а нравственный подчеркивает потенциальные затраты от этого действия. Ценность комбинированной когнитивно-эмотивной модели в том, что эмоции могут дать принимающему решение более значимую информацию, чем чистое рассуждение. Это произойдет при условии, что (1) гедонистические эмоции адекватно модулированы с помощью познавательной сферы и серотонина, (2) гедонистические эмоции не усилены стрессом или стесненными жизненными обстоятельствами либо реактивным криминальным мышлением, (3) нравственные эмоции хорошо развиты и (4) нравственные эмоции не подавлены проблемами статуса или идентичности либо проактивным криминальным мышлением.

Понимание природы криминального принятия решений помогает также разобраться, как человек вообще принимает решение (например, биологические факторы и факторы окружения; затраты и выгоды; внутренние и внешние факторы; влияние эмоций и рас- суждений). Работа также показывает необходимость системы модулированных гедонистических эмоций и хорошо развитых нравственных эмоций. Результаты исследования будут также полезны тем, кто разрабатывает программы коррекции преступников, например, с области влияния ситуативных, психических факторов и криминального мышления на процесс принятия решений. Данная модель расширяет как нормативную модель Cornish и Clarke [11, 12], так и теорию «достаточности» [14], являясь дескриптивной моделью, объединяющей рациональные и нерациональные компоненты из ТРВ, психологические и экономические теории выбора и теорию криминального образа жизни. Поскольку лишь отдельные аспекты этой модели до настоящего времени прошли апробацию, необходимы дальнейшие исследования для более глубокой оценки как модели, так и теории, лежащей в ее основе. Соответственно, было выдвинуто десять гипотез в соответствии с направлениями будущих исследований. Они призваны выяснить, дает ли наша теория новое понимание преступности, преступников и процесса принятия криминальных решений.

В заключение хотим отметить, что данная работа не предполагала полного анализа или обзора литературы по проблеме процесса принятия криминальных решений. Такой обзор потребовал бы как минимум семи подобных статей (связь эмоций и выбора; нейроанатомические основы; контекст психологии развития; роль темперамента; гедонистические эмоции и ожидания; нравственные эмоции и ожидания; проактивное и реактивное криминальное мышление). Мы предлагаем не столько подробный разбор одного из аспектов, сколько широкий обзор всей модели. По этой причине представленный обзор литературы отличается выборочностью и краткостью, хотя мы старались сделать его максимально беспристрастным и сбалансированным. Дальнейшую работу над данной моделью мы планируем начать с более глубокой оценки каждого ее элемента и рассмотрения взаимосвязи между элементами по направлениям, обозначенным в десяти гипотезах, выдвинутых в данной работе.

\section{Список литературы / References}

1. Paternoster, R. (2010). How much do we know about criminal deterrence? Journal of Criminal Law and Criminology, 100(3), 765-823.

2. Cohen, L., \& Felson, M. (1979). Social change and crime rate trends: A routine activity approach. American Sociological Review, 44(4), 588-608.

Уолтерс Г. Рациональность и нерациональность решения о совершении преступления

Walters G. D. Decision to commit crime: rational or nonrational 
3. Akers, R. L. (1998). Social learning and social structure: A general theory of crime and deviance. Boston, MA: Northeastern University Press.

4. Agnew R. Foundation for a general strain theory of crime and delinquency // Criminology. 1992. Vol. 30. No. 1. Pp. 47-87.

5. Tedeschi, J., \& Felson, R. B. (1994).Violence, aggression, and coercive actions. Washington, DC: American Psychological Association.

6. Gottfredson, M., \& Hirschi, T. (1990).A general theory of crime. Stanford, CA: Stanford University Press.

7. Clarke, R. V. (2009). Situational crime prevention: Theoretical background and current practice. in M. D. Krohn, A. J. Lizotte, \& G. P. Hall (Eds.), Handbook of crime and deviance (pp. 259-276). New York, NY: Springer.

8. Gul, S. (2009). An evaluation of rational choice theory in criminology. Girne American University Journal of Sociology and Applied Science, 4(8), 36-44.

9. Becker, G. S. (1968). Crime and punishment: An economic approach. Journal of Political Economy, 76, 169-217.

10. Schmidt, P., \& Witte, A. D. (1984). An economic analysis of crime and justice. New York, NY: Academic Press.

11. Cornish, D. B., \& Clarke, R. V. (1985). Modeling offenders decisions: A framework for research and policy. In M. Tonry \& N. Morris (Eds.), Crime and justice: An annual review of research (Vol. 6, pp. 147-185). Chicago, IL: University of Chicago Press.

12. Cornish, D. B., \& Clark, R. V. (Eds.). (1986).The reasoning criminal: Rational choice perspectives on offending. New York, NY: Springer.

13. Clarke, R. V. (2014). Affect and the reasoning criminal: Past and future. In J. L. Van Gelder, H. Elffers, D. Reynald, \& D. Nagin (Eds.), Affect and cognition in criminal decision-making (pp. 20-41). London, England: Routledge.

14. Wortley, R. (2014). Rational choice and offender decisionmaking: Lessons from the cognitive sciences. In B. Leclerc \& R. Wortley (Eds.), Cognition and crime: Offender decision-making and script analysis (pp. 237-252). London, England: Routledge.

15. De Haan, W., \& Vos, J. (2003). A crying shame: The over-rationalized conception of man in the rational choice perspective. Theoretical Criminology,7(1), 29-54. doi: 10.1177/1362480603007001199

16. Hayward, K. (2007). Situational crime prevention and its discontents: Rational choice theory versus the 'culture of now.' Social Policy and Administration,41(3), 232-250. DOI: 10.1111/j.1467-9515.2007.00550.x

17. Zafirovski, M. (2012). Beneath rational choice: Elements of 〈irrational choice theory.〉 Current Sociology, 61, 3-21. DOI: $10.1177 / 0011392112465872$

18. Pratt, T. C., \& Cullen, F. T. (2005). Assessing macrolevel predictors and theories of crime: A meta-analysis. Crime and Justice, 32, 373-450.

19. Lindegaard, M. R., Bernasco, W., Jacques, S., \& Zenebergen, B. (2014). Posterior gains and immediate pains: Offender emotions before, during and after robberies. In J.-L.
Van Gelder, H. Elffers, D. Reynald, \& D. Nagin (Eds.), Affect and cognition in criminal decision-making (pp. 58-76). London, England: Routledge.

20. Bouffard, J. (2014). The role of sexual arousal and perceived consequences in men's and women's decisions to engage in sexually coercive behaviours. In J.-L. Van Gelder, H. Elffers, D. Reynald, \& D. Nagin (Eds.), Affect and cognition in criminal decision-making (pp. 77-96). London, England: Routledge.

21. Van Gelder, J.-L., Reynald, D., \&Elffers, H. (2014). Anticipated emotions and immediate affect in criminal decisionmaking: From shame to anger. In J.-L. Van Gelder, H. Elffers, D. Reynald, \& D. Nagin (Eds.), Affect and cognition in criminal decision-making (pp. 161-178). London, England: Routledge.

22. Forgas, J. P. (1991). Affective influences on partner choice: Role of mood in social decisions. Journal of Personality and Social Psychology, 61(5), 708-720. DOI: 10.1037/0022 3514.61 .5 .708

23. Gordon, C., \& Arian, A. (2001) Threat and decisionmaking. Journal of Conflict Resolution, 45(2), 196-215. DOI: 10.1177/0022002701045002003

24. Martin, L. N., \& Delgado, M. R. (2011). The influence of emotion regulation on decision-making under risk. Journal of Cognitive Neuroscience,23(9), 2569-2581. DOI: 10.1162/ jocn.2011.21618

25. Damasio, A. (1994).Descartes' error: Emotion, reason, and the human brain. New York, NY: Putnam.

26. Bechara, A., Damasio, H., \& Damasio, A. R. (2000). Emotion, decision-making and the orbitofrontal cortex. Cerebral Cortex,10(3), 295-307. DOI: 10.1093/cercor/10.3.295

27. Beer, J. S., Knight, R. T., \& D’Esposito, M. (2006). Controlling the integration of emotion and cognition: The role of frontal cortex in distinguishing helpful from hurtful emotional information. Psychological Science,17(5), 448-453. DOI: 10.1111/j.1467-9280.2006.01726.x

28. Shamay-Tsoory, S. G., Harari, H., Aharon-Peretz, J., \& Levkovitz, Y. (2010). The role of the orbitofrontal cortex in affective theory of mind deficits in criminal offenders with psychopathic tendencies. Cortex,46(5), 668-677. DOI: I0.1016/j. cortex.2009.04.008

29. Everitt, B. J., Cardinal, R. N., Parkinson, J. A., \& Robbins, T. W. (2003). Appetitive behavior: Impact of amygdaladependent mechanisms of emotional learning. Annals of the New York Academy of Sciences, 985, 233-250. DOI: 10.1111/j.17496632.2003.tb07085.x

30. Gupta, R., Koscik, T. R., Bechara, A., \& Tranel, D. (2011). The amygdala and decision-making. Neuropsychologia, 49(4), 760-766. DOI: 10.1016/j.neuropsychologia.2010.09.029

31. Sokol-Hessner, P., Camerer, C. F., \& Phelps, E. A. (2013). Emotion regulation reduces loss aversion and decreases amygdala responses to losses. Social Cognitive and Affective Neuroscience, 8, 341-350. DOI: I0.1093/scan/nss002

32. Glenn, A. L., \& Yang, Y. L. (2012). The potential role of the striatum in antisocial behavior and psychopathy. Biological Psychiatry,72(10), 817-822. DOI: 10.1016/j.biopsych.2012.04.027 
33. Blakemore, S. J., \& Robbins, T. W. (2012). Decisionmaking in the adolescent brain. Nature Neuroscience, 15, 1184-1191. DOI: 10.1038/nn.3177

34. Arsenio, W., Adams, E., \& Gold, J. (2009). Social information processing, moral reasoning and emotion attributions: Relations with adolescents' reactive and proactive aggression. Child Development, 80(6), 1739-1755. DOI: 10.1111/j.1467-8624.2009.01365.x

35. Malti, T., Keller, M., \& Buchmann, M. (2012). Do moral choices make us feel good? The development of adolescents> emotions following moral decision-making. Journal of Research on Adolescence, 23(2), 389-397. DOI: 10.1111/jora.12005

36. Premack, D. G., \& Woodruff, G. (1978). Does the chimpanzee have a theory of mind? Behavioral and Brain Sciences, 1(4), 515-526. DOI: 10.1017/S0140525X00076512

37. Sebastian, C. L., Fontaine, N. M. G., Bird, G., Blakemore, S.-J., DeBrito, S. A., McCrory, E. J. P., \& Viding, E. (2012). Neural processing associated with cognitive and affective theory of mind in adolescents and adults. Social Cognitive and Affective Neuroscience, 7(1), 56-63. DOI: I0.1093/scan/nsr023

38. Rothbart, M. K. (2007). Temperament, development and personality. Current Directions in Psychological Science, 16(4), 207-212. DOI: 10.1111/j.1467-8721.2007.00505.x

39. Kagan, J. (2010). Emotions and temperament. In M. H. Burnstein (Ed.), Handbook of cultural developmental science (pp. 175-194). New York, NY: Psychology Press.

40. Walters, G. D. (2012).Crime in a psychological context: From career criminals to criminal careers. Thousand Oaks, CA: Sage.

41. Cherbuin, N., Windsor, T. D., Anstey, K. J., Maller, J. J., Meslin, C., \& Sachdeve, P. S. (2008). Hippocampal volume is positively associated with behavioural inhibition (BiS) in a large community-based sample of mid-life adults: The PATH through life study. Social Cognitive and Affective Neuroscience, 3, 262-269. DOI: 10.1093/scan/nsn018

42. Sah, P., Faber, E. S. L., Lopez de Armentia, M., \& Power, J. (2003). The amygdaloid complex: Anatomy and physiology. Physiology Review, 83(3),803-834. DOI: 10.1152/ physrev.00002.2003

43. Walters, G. D., \& Kiehl, K. A. (in press). Limbic correlates of fearlessness and disinhibition in incarcerated youth: Exploring the brain-behavior relationship with the Hare Psychopathy Checklist: Youth Version. Psychiatry Research. Advance online publication. DOI: 10.1016/j.psychres.2015.08.041

44. Walters, G. D. (2015). A two-dimensional model of psychopathy and antisocial behavior: A multi-sample investigation using items from the Psychopathy ChecklistRevised. Personality and Individual Differences, 78, 88-93. DOI: 10.1016/j.paid.2015.01.037

45. Tangney, J. P., Stuewig, J., \& Mashek, D. J. (2007). Moral emotions and moral behavior. Annual Review of Psychology, 58, 345-372. DOI: I0.1146/annurev.psych.56.091103.070145

46. Loewenstein, G., \& Lerner, J. S. (2003). The role of affect in decision-making. In R. J. Davidson, K. R. Scherer, \&
H. H. Goldsmith (Eds.) Handbook of affective sciences (pp. 619-642). New York, NY: Oxford University Press.

47. Krettenauer, T., Jia, F., \& Mosleh, M. (2011). The role of emotion expectancies in adolescents $>$ moral decision-making. Journal of Experimental Child Psychology, 108(2), 358-370. DOI: 10.1016/j.jecp.2010.08.014

48. Kahneman, D., \& Tversky, A. (1973). On the psychology of prediction. Psychological Review, 80(4), 237-251. DOI: $10.1037 / \mathrm{h} 0034747$

49. Kahneman, D., \& Tversky, A. (1979). Prospect theory: An analysis of decisions under risk. Econometrica, 47(2), 263-291. DOI: $10.2307 / 1914185$

50. Tversky, A., \& Kahneman, D. (1974). Judgment under uncertainty: Heuristics and biases. Science, 185(4157), $1124-$ 1131. DOI: I0.1126/science.185.4157.1124

51. Bowen, K. N., Roberts, J. J., Kocian, E. J., \& Bartula, A. (2014). An empirical test of social information processing theory and emotions in violent situations. Western Criminology Review, 15, 18-33.

52. Angie, A. D., Connelly, S., Waples, E. P., \& Kligyte, V. (2011). The influence of discrete emotions on judgement and decision-making: A meta-analytic review. Cognition and Emotion, 25(8), 1393-1422. DOI: 10.1080/02699931.2010.550751

53. Marcus, B. (2004). Self-control in the general theory of crime: Theoretical implications of a measurement problem. Theoretical Criminology, 8(1), 33-55. DOI: $10.1177 / 1362480604039740$

54. Arantes, J., Berg, M. E., Lawlor, D., \& Grace, R. C. (2013). Offenders have higher delay-discounting rates than nonoffenders after controlling for differences in drug and alcohol abuse. Legal and Criminological Psychology, 18(2), 240-253. DOI: $10.1111 / \mathrm{j} .2044-8333.2012 .02052 . \mathrm{x}$

55. Hanoch, Y., Rolison, J., \& Gummerum, M. (2013). Good things come to those who wait: Time discounting differences between adult offenders and nonoffenders. Personality and Individual Differences, 54(1), 128-132. DOI: 10.1016/j.paid.2012.08.025

56. Varghese, F. P., Charlton, S. R., Wood, M., \& Trower, E. (2014). Temporal discounting and criminal thinking: Understanding cognitive processes to align services. Psychological Services, 11(2), 171-178. DOI: I0.1037/a0035004

57. Maruna, S., \& Copes, H. (2005). What have we learned from five decades of neutralization research? Crime and Justice: A Review of Research, 32, 221-320.

58. Sykes, G. M., \& Matza, D. (1957). Techniques of neutralization: A theory of delinquency. American Sociological Review, 22(6), 667-670.

59. Earley, P. (1992). The hot house: Life inside Leavenworth prison. New York, NY: Bantam.

60. Woodworth, M., \& Porter, S. (2002). In cold blood: Characteristics of criminal homicides as a function of psychopathy. Journal of Abnormal Psychology, 111(3), 436-445. DOI: $10.1037 / 0021-843 X .111 .3 .436$

61. Beauregard, E., Rossmo, K., \& Proulx, J. (2007). A descriptive model of the hunting process of serial sex offenders: 
A rational choice perspective. Journal of Family Violence, 22(6), 449-463. DOI: 10.1007/s10896-007-9101-3

62. Albanese, J. S. (2000). The causes of organized crime: Do criminals organize around opportunities for crime or do criminal opportunities create new offenders? Journal of Contemporary Criminal Justice, 16(4), 409-423. DOI: 10.1177/1043986200016004004

63. Felson, R. B. (1993). Predatory and dispute-related violence: A social interactionist approach. In R. V. Clarke \& M. Felson (Eds.), Advances in criminological theory (Vol. 5, pp. 189-235). New Brunswick, NJ: Transaction.

64. Feeney, F. (1986). Robbers as decision-makers. In D. B. Cornish \&R. V. G. Clarke (Eds.), The reasoning criminal: Rational choice perspectives on offending (pp. 53-71). New York, NY: Springer-Verlag.

65. Monahan, B. A., Marolla, J. A., \& Bromley, D. G. (2005). Constructing coercion: The organization of sexual assault. Journal of Contemporary Ethnography, 34(3), 284-316. DOI: $10.1177 / 0891241605274555$

66. Felson, R. B., \& Massoglia, M. (2012). When is violence planned? Journal of Interpersonal Violence, 27(4), 753-774. DOI: 10.1177/0886260511423238

67. Loughran, T. A., Piquero, A. R., Fagan, J., \& Mulvey, E. P. (2012). Differential deterrence: Studying heterogeneity and changes in perceptual deterrence among serious youthful offenders. Crime and Delinquency, 58(1), 3-27. DOI: 10.1177/0011128709345971

68. American Psychiatric Association. (2013). Diagnostic and statistical manual of mental disorders (5th ed.). Washington, DC: Author.

69. Frick, P. J., Ray, J. V., Thornton, L. C., \& Kahn, R. E. (2014). Can callous-unemotional traits enhance the understanding, diagnosis, and treatment of serious conduct problems in children and adolescents? A comprehensive review. Psychological Bulletin, 140(1), 1-57. DOI: 10.1037/a0033076

70. Viding, E., Price, T. S., Jaffee, S. R., Trzaskowski, M., Davis, O. S. P., Meaburn, E. L., Haworth, C. M. A., \& Plomin, R. (2013). Genetics of callous-unemotional behavior in children. PLoS One, 8, 1-9. DOI: 10.1371/journal.pone.0065789

71. Mulvey, E. P. (2012, November). The Pathways to Desistance Study: Design and methods. Paper presented at the American society of Criminology Annual Meeting, Chicago, IL. Retrieved from http:// citation.allacademic.com/meta/p574246 in dex.html

72. Andershed, H., Kerr, M., Stattin, H., \& Levander, S. (2002). Psychopathic traits in non-referred youths: Anew assessment tool. In E. Blaauw \&L. Sheridan (Eds.), Psychopaths: Current international perspectives (pp. 131-158). The Hague, Netherlands: Elsevier.

73. Steffensmeier, D., Allan, E., Harer, M., \& Streifel, C. (1989). Age and the distribution of crime. American Journal of Sociology, 94(4), 803-831.

74. Hirschi, T., \& Gottfredson, M. (1983). Age and the explanation of crime. American Journal of Sociology, 89(3), 522-584.

75. Steffensmeier, D., \& Harer, M. D. (1999). Making sense of recent U.S. crime trends, 1980 to 1996/1998: Age composition (C) Уолтерс Г., 2016. effects and other explanations. Journal of Research in Crime and Delinquency, 36(3), 235-274.

76. Kanazawa, S., \& Still, M. C. (2000). Why men commit more crimes (and why they desist). Sociological Theory, 18(3), 434- 447.

77. Soderstrom, H., Blennow, K., Sjodin, A.-K., \& Forsman, A. (2003). New evidence for an association between the CSF HVA:5HIAA ratio and psychopathic traits. Journal of Neurology, Neurosurgery, and Psychiatry, 74, 918-921. DOI: I0.1136/jnnp.74.7.918

78. Butler, T., Schofield, P. W., Greenberg, D., Allnutt, S. H., Indig, D., Carr, \& Ellis, A. (2010). Reducing impulsivity in repeat violent offenders: An open label trial of a selective serotonin reuptake inhibitor. Australian and New Zealand Journal of Psychiatry, 44(12), 1137-1143. DOI: 10.3109/00048674.2010.525216

79. Walsh, M. T., \& Dinan, T. G. (2001). Selective serotonin reuptake inhibitors and violence: A review of the available evidence. Acta Psychiatrica Scandinavica, 104(2), 84-91.

80. Healy, D., Langmaack, C., \& Savage, M. (1999). Suicide in the course of the treatment of depression. Journal of Psychopharmacology, 13(1), 94-99. DOI:10.1177/026988119901300110

81. Lipsey, M. W., Wilson, D. B., \& Cothern, L. (2000, April). Effective intervention for serious juvenile offenders. Juvenile Justice Bulletin. Washington DC: Office of Justice Program, U.S. Department of Justice.

82. Walters, G. D. (2009). Anger management training in incarcerated male offenders: Differential impact on proactive and reactive criminal thinking. International Journal of Forensic Mental Health, 8(3), 214-217. DOI: 10.1080/14999010903358995

83. Wilson, D. B., Bouffard, L. A., \& MacKenzie, D. L. (2005). A quantitative review of structured, group-oriented, cognitive-behavioral programs for offenders. Criminal Justice and Behavior, 32(2), 172-204. DOI: 10.1177/0093854804272889

84. Goldstein, T. R., \& Winner, E. (2012). Enhancing empathy and theory of mind. Journal of Cognition and Development, 13(1), 19-37. DOI: $10.1080 / 15248372.2011 .573514$

85. Clear, T. R. (1994). Harm in American penology: Offenders, victims, and their communities. Albany, NY: State University of New York Press.

86. MacKenzie, D. L. (2000). Evidence-based corrections: Identifying what works. Crime and Delinquency, 46(4), 457-471. DOI: $10.1177 / 0011128700046004003$

87. Pratt, T. C. (2008). Rational choice theory, crime control policy, and criminological relevance. Criminology and Public Policy, 7(1), 43-52. DOI: 10.1111/j.1745-9133.2008.00489.x

88. Walters, G. D. (1995). The Psychological Inventory of Criminal Thinking Styles: Part I. Reliability and preliminary validity. Criminal Justice and Behavior,22(3), 307-325. doi: 10.1177/0093854895022003008

89. Walters, G. D. (2015). Decision to Commit Crime: Rational or Nonrational, Criminology, Criminal Justice, Law \& Society and The Western Society of Criminology Hosting by Scholastica, 16 (3), 1-18.

Дата поступления 14.06.2016 Дата принятия в печать 28.07.2016 Дата онлайн-размешения 20.09.2016 


\section{Информация об авторе}

Уолтерс Гленн, доктор философии, доцент кафедры уголовного правосудия, Университет Куцтаун Адрес: 19530, США, шт. Пенсильвания, г. Куцтаун, Куцтаун роуд, 15200 , E-mail: walters@kutztown.edu

\section{G. D. WALTERS ${ }^{1}$}

${ }^{1}$ Kutztown University, USA

\section{DECISION TO COMMIT CRIME: RATIONAL OR NONRATIONAL*}

Objective: to prove the necessity to take into account the influence of emotions on decision making; to describe a combined model of the decision making process which unites rational and irrational components of choice in crime commitment.

Methods: dialectic, systemic, historical-legal, formal-juridical methods, summarization.

Results: the paper gives a complex analysis of the criminal decision-making process, and reveals the factors increasing the probability of antisocial actions. The value of the combined cognitive-emotive model is that emotions can give more significant information to the decision-maker, than reasoning.

Scientific novelty: the author proposes a theory of decision making which says that a person chooses to act or not to act under hedonistic or moral emotions, while the irrelevant emotions are increased and the relevant ones are suppressed by cognitive and situational factors serving as a basis for criminal decision making.

Practical significance: studying the role of emotions in the criminal and non-criminal decision making will significantly contribute to the development of criminology. The research results will be useful for researchers and law-enforcement bodies, as well as for all those who are interested in the issues of crime control and prevention.

Keyword: Rational choice theory; Moral emotions; Hedonistic emotions; Proactive criminal thinking; Reactive criminal thinking

Received 14.06.2016

Accepted 28.07.2016

Available online 20.09.2016

(C) Glenn D. Walters, 2016.

* Published by Criminology, Criminal Justice, Law \& Society and The Western Society of Criminology Hosting by Scholastica. All rights reserved.This is an Open Access article distributed under the terms of the Creative Commons Attribution Non-Commercial License (http://creativecommons.org/licenses/by-nc/3.0/), which permits non-commercial re-use, distribution, and reproduction in any medium, provided the original work is properly cited. For commercial use, see Criminology, Criminal Justice, Law \& Society (CCJLS) and The Western Society of Criminology: CCJLS@WesternCriminology.org.

For original publication: Walters G. D. (2015). Decision to Commit Crime: Rational or Nonrational, The. Criminology, Criminal Justice, Law \& Society, 16, 1.

\section{Information about the author}

Glenn D. Walters, Ph.D., Associate Professor of Criminal Justice, Kutztown University, USA

Address: 15200 Kutztown Rd., Kutztown, Pennsylvania, 19530, USA

E-mail: walters@kutztown.edu

For citation of Russian version: Walters G. D. Decision to commit crime: rational or nonrational, Actual Problems of Economics and Law, 2016, vol. 10, No. 3, pp. 252-270. DOI: http://dx.doi.org/10.21202/1993-047X.10.2016.3.252-270 